\title{
Adesão leucocitária e MDA sérico em cães naturalmente infectados por Leishmania infantum*
}

\section{Leukocyte adhesion and MDA serum levels in naturally infected dogs by Leishmania infantum}

Glauco Jonas Lemos Santos, ${ }^{* *}$ Adam Leal Lima, ${ }^{* *}$ Belarmino Eugênio Lopes-Neto, ${ }^{* *}$ José Cláudio Carneiro de Freitas, ${ }^{* *}$ Fernanda Maria Machado Maia, ${ }^{* * *}$ Diana Célia Sousa Nunes-Pinheiro**

\begin{abstract}
Resumo
O presente estudo avaliou o estresse oxidativo e a adesão de leucócitos (AL) em cães naturalmente infectados por Leishmania infantum. Foram utilizados cães saudáveis $(C N=10)$ e cães acometidos por leishmaniose visceral na forma sintomática $(C S=10)$, submetidos previamente a exames de imunofluorescência indireta (IFI), ensaio imunoenzimático (ELISA) e pesquisa do parasito em aspirados de medula óssea. Soro foi utilizado para avaliação de malondialdeído (MDA) no ensaio para espécies reativas ao ácido tiobarbitúrico (TBARS) e AL foi determinada pelo método da coluna de náilon em sangue em EDTA, heparina e citrato. Os dados de AL foram expressos em porcentagem e MDA em média \pm desvio padrão, submetidos ao teste T de student não pareado $(p<0,05)$. Amostras em heparina apresentaram níveis mais elevados de AL no grupo CS $(55,62 \%, p<0,05)$ quando comparadas com EDTA e citrato (10,46\% e 5,28\%). Citrato e EDTA inibiram AL em cães doentes e saudáveis, enquanto a heparina preservou a AL. A proporção neutrofílica se apresentou reduzida nas amostras em heparina $(85 \%$ para $67 \%, p<0,05)$ quando comparadas com citrato e EDTA, que por sua vez mantiveram-se estáveis (83\% para $80 \%$ ). Os níveis de MDA apresentaram-se mais elevados em CS $(0,0117 \mu \mathrm{M} \pm 0,002)$ quando comparado com $\mathrm{CN}(0,0057 \mu \mathrm{M} \pm 0,001)(p<0,05)$. Estes dados dão suporte à conclusão de que na LVC ocorre elevação do estresse oxidativo e aumento da expressão das moléculas de adesão nos leucócitos, evidenciando resposta inflamatória sistêmica. A escolha do anticoagulante é importante para a implementação do ensaio de $A L$.
\end{abstract}

Palavras-chave: agregação leucocitária, anticoagulantes, estresse oxidativo, leishmaniose visceral canina.

\begin{abstract}
The present study evaluated the oxidative stress and leukocyte adhesion (LA) in dogs naturally infected by Leishmania infantum. Healthy dogs $(H D=10)$ and dogs affected by canine visceral leishmaniasis $(C V L)$ in symptomatic form $(S D=10)$ were previously submitted to indirect immunofluorescence reaction (IIF), enzyme-linked immunosorbent assay (ELISA) and detection of parasites in bone marrow aspirates. Serum was used to assess malondialdeid (MDA) by thiobarbituric acid reactive species (TBARS) assay and $A L$ was determined by nylon column method using whole blood stored in EDTA, citrate and heparin. AL data was expressed as percentage and MDA data as mean \pm standard deviation, both submitted to the unpaired student's T test $(p<0.05)$. Heparin samples showed higher levels of AL in CS group (55.62 \%, p < 0.05) when compared with EDTA and citrate (10.46\% and 5.28\%). Citrate and EDTA inhibit AL in healthy and sick dogs, while heparin preserved AL in both groups. Neutrophil proportion in heparin samples were lower $(85 \%$ to $67 \%, p<0.05)$ compared with citrate and EDTA, which in turn remained practically unchanged ( $83 \%$ to $80 \%)$. MDA levels were higher in SD $(0.0117 \mu \mathrm{M} \pm 0.002)$ when compared to HD $(0.0057 \mu \mathrm{M} \pm 0.001)(p<0.05)$. These data support the conclusion that CVL induces oxidative stress enhance and leukocyte adhesion increase, indicating systemic inflammatory response. The choice of anticoagulant is an important decision for implementing LA assays.
\end{abstract}

Keywords: anticoagulants, canine visceral leishmaniasis, leukocyte adhesion, oxidative stress.

\section{Introdução}

A dinâmica do processo inflamatório envolve uma série de eventos que inclui mecanismos celulares e moleculares (Engelhardt e Ransohoff, 2012). A execução desse processo envolve a ativação das células, liberação de mediadores e aumento da expressão das moléculas de adesão, receptores de superfície específicos que promovem a migração transendotelial dos leucócitos através do endotélio vascular ativado (Shalekoff et al., 1998, Kolaczkowska e Kubes, 2013).
As moléculas de adesão coordenam as várias fases da adesão leucocitária $(A L)$ ao endotélio inflamado quiescente por meio de um mecanismo regulado por ligação com receptores e citocinas (Mazzone e Ricevuti, 1995; Margadant et al., 2011). O controle destas interações permite que os leucócitos possam aderir à parede do vaso, a locomoção e a migração de leucócitos para os tecidos (Muller, 2009, Weninger et al., 2014).

Existem muitos fatores que afetam a AL (Adams e Nash, 1996), seja amplificando-a, a exemplo das toxinas bacterianas e

\footnotetext{
*Recebido em 31 de outubro de 2014 e aceito em 19 de abril de 2016.

**Laboratório de Imunologia e Bioquímica Animal / Universidade Estadual do Ceará (UECE), Avenida Paranjana, 1700, CEP 60740-002, Campus do Itaperi, Fortaleza, Ceará, Brasil.*E-mail adress: glaucojonasls@hotmail.com; diana.pinheiro@uece.br.

***Laboratório de Nutrição Funcional - Centro de Ciências Biomédicas/Universidade Estadual do Ceará (UECE), Avenida Paranjana, 1700, CEP 60740-002, Campus do Itaperi, Fortaleza, Ceará, Brasil.
} 
citocinas pró-inflamatórias IL-1 e TNF (Bevilacqua et al., 1994), ou suprimindo-a, como as doenças genéticas que levam a alterações na formação das moléculas de adesão (Debenham et al., 2002). Lidocaína (MacGregor et al., 1980), anticoagulantes (Dhondt et al., 1998), temperatura, tempo de armazenamento (Holst et al., 2011) e doenças de natureza genética (Nagahata et al., 2004; Kobayashi et al., 2009) ou autoimunes (Shelef et al., 2013). Portanto, estas situações modulam a migração de leucócitos, comprometendo os eventos posteriores que culminarão com a destruição do agente invasor, por meio da fagocitose e do estresse oxidativo (Andrew, 2012).

O processo que utiliza um elevado consumo de oxigênio plasmático conhecido como estresse oxidativo é ativado quando o complexo enzimático NADPH-oxidase (NOX) é formado na membrana do fagócito, o que resulta na geração de produtos microbicidas conhecidos como espécies reativas de oxigênio (ROS), elementos importantes na resposta do organismo frente a agentes infecciosos que causam doenças (Segal, 2005).

As leishmanioses são um complexo zoonótico que impõe sérios problemas de saúde pública (Brasil, 2014). Trata-se de enfermidades causadas por protozoários do gênero Leishmania, carreados pelo inseto vetor do gênero Lutzomyia e Phlebotomus. O cão doméstico e o homem são listados como principais hospedeiros definitivos nos centros urbanos (Gontijo e Melo, 2004). A entrada e sobrevivência da Leishmania spp. dentro dos macrófagos é possível mediante infecção direta ou através da remoção de neutrófilos infectados e recrutados como uma resposta natural à picada do inseto (Zandbergen et al., 2004; Jochim e Teixeira, 2009).

A resposta a Leishmania spp. pode ser medida por mediadores inflamatórios como proteína C reativa (Lopes-Neto, 2015), mediadores do estresse oxidativo e antioxidantes totais (Baldissera et al., 2015), por citocinas séricas (Freitas et al., 2014), entre outros. Neste contexto, o presente estudo teve como objetivo avaliar a adesão leucocitária (AL) e o estresse oxidativo sistêmico em cães naturalmente infectados por Leishmania infantum.

\section{Material e métodos}

\section{Animais}

Foram utilizados cães adultos $(n=10)$ de ambos os sexos (CN: 4 machos e 6 fêmeas; CS: 5 machos e 5 fêmeas), com peso, idade e raças variadas. Os animais foram obtidos em cooperação com o Centro de Controle de Zoonoses (CCZ) do município de Fortaleza. Neste estudo, os animais naturalmente infectados apresentavam leishmaniose visceral canina (LVC) na forma sintomática e compuseram o grupo cães sintomáticos / soropositivos (CS). Foram considerados sinais clínicos da LVC: alopecia moderada generalizada e/ou localizada, onicogrifose, perda de peso grave, lesões na pele, ceratoconjutivite e linfadenomegalia. Cães saudáveis $(n=10)$ foram obtidos em cooperação com um canil privado. Estes animais por sua vez eram soronegativos para $L$. infantum e compuseram o grupo cães negativos $(\mathrm{CN})$. O protocolo experimental foi aprovado pelo Comitê de Ética em Uso de Animais da Universidade Estadual do Ceará, Brasil (CEUA / UECE), número 08622833-1 e todos os procedimentos seguiram as técnicas preconizadas de bemestar animal em experimentação científica.

\section{Triagem sorológica e parasitológica dos animais}

Todos os animais foram submetidos previamente a exames de imunofluorescência indireta (IFI) kit IFIcanine leishmanioseBio-Manguinhos (IFI-LC) e ensaio imunoenzimático (ELISA) - LES-leishmaniose canina-Bio-Manguinhos (LES-LC). Foram considerados positivos os animais que apresentaram titulação $\geq 1: 40$ em ambos os testes. O diagnóstico sorológico da LVC foi realizado no $\mathrm{CCZ}$ por meio de kits padronizados fornecidos pela Bio-Manguinhos/Fiocruz, Rio de Janeiro, Brasil, e todos os procedimentos foram realizados de acordo com o manual técnico de instruções (Lira et al., 2006). Os animais também foram submetidos a exame parasitológico em aspirados de medula óssea para confirmar a infecção. Para tanto, os animais foram anestesiados com xilazina (2 mg/kg, Rompun ${ }^{\circledR}$, Bayer Healthcare Brasil, Brasil) e cetamina $\left(10 \mathrm{mg} / \mathrm{kg}\right.$, Dopalen ${ }^{\circledast}$, Agribrands Brasil Ltda., Brasil). As amostras foram fixadas, coradas e examinadas por microscopia óptica para avaliar a presença de formas amastigotas de Leishmania spp.

\section{Os grupos experimentais}

Os animais foram divididos em dois grupos, cães saudáveis $(C N, n=10)$ e cães sintomáticos para LVC causada por infecção por $L$. infantum (CS, $n=10$ ). Cães positivos também foram selecionados de acordo com a apresentação de sinais clínicos e soropositividade para $L$. infantum. Cães soronegativos para $L$. infantum, sem sinais clínicos característicos da leishmaniose e/ ou de qualquer outra doença foram incluídos no grupo $\mathrm{CN}$. Todos os animais foram submetidos a exames de imunofluorescência indireta (IFI), ensaio imunoenzimático (ELISA) e pesquisa do parasito em aspirados de medula óssea.

\section{Amostras de sangue}

Amostras de sangue (15 mL) foram colhidas por venipunção jugular de cada animal em ambos os grupos por meio de seringas estéreis e distribuídos em tubos contendo anticoagulantes heparina, EDTA (ácido etilenodiaminotetracético) e citrato (Vacutainer ${ }^{\circledR}$, BD Franklin Lakes, $N J$, EUA) e em tubo contendo gel ativador. As amostras de sangue coletadas em anticoagulantes foram utilizadas para avaliação de hemograma completo e teste de AL. As amostras de soro obtidas foram armazenadas a $-20^{\circ} \mathrm{C}$ até uso para a análise de MDA (malondialdeído) pelo teste TBARS (espécies reativas ao ácido tiobarbitúrico)

\section{Avaliação hematológica}

Amostras de sangue em heparina, EDTA e citrato foram homogeneizadas e submetidas a aparelho de contagem hematológica automatizada (Hema tela $\AA$ 18, HOSPITEX Diagnostics, Firenze, Itália) em duas fases: pré-processamento (PRE) e pós-processamento (POS). Os parâmetros hematológicos avaliados foram: leucócitos totais (LT, 103/ $\mathrm{mL})$, eritrócitos totais $\left(\mathrm{ET}, 10^{6} / \mathrm{mL}\right)$, hemoglobina $(\mathrm{Hb}, \mathrm{g} / \mathrm{dL})$, determinação do hematócrito $(\mathrm{Ht}, \%)$ e plaquetas $\left(\mathrm{Pt}, 10^{3} /\right.$ $\mu \mathrm{L}$ ). A contagem diferencial (neutrófilos, eosinófilos, basófilos, monócitos e linfócitos) foi realizada por meio de esfregaço sanguíneo corado, a fim de se avaliar as mudanças resultantes na proporção neutrofílica induzida pelo teste de AL. Os esfregaços foram também cuidadosamente avaliados para a presença de hemoparasitas (Erlichia spp., Babesia spp., Dirofilaria spp.), como critério de exclusão de animais. 


\section{Avaliação da adesão de leucócitos}

A taxa de $\mathrm{AL}$ foi determinada pelo método da coluna de náilon tal como descrito por MacGregor com algumas modificações (MacGregor et al., 1980). Para tanto, fibra sintética mista comercial (náilon $84 \%$, elastano 16\%) foi utilizada em colunas de adesão montadas em seringas plásticas estéreis e descartáveis de $1 \mathrm{ml}$. A fibra foi compactada em $17 \mathrm{~mm}$ de altura. As seringas foram mantidas em posição vertical e acopladas a tubos plástico estéreis na sua extremidade inferior (Labware Manufacturing Co. $®$, China). Resumidamente, um mililitro de sangue total em heparina, EDTA e citrato previamente submetidos a análises hematológicas na fase de pré-processamento (PRE) foram adicionados lentamente na extremidade superior de cada coluna de adesão, sendo recuperado no tubo plástico estéril na porção inferior. Ao final do gotejamento, o sangue foi então submetido a uma nova análise hematológica na fase de pós-processamento (POS) e as contagens de LT nas duas fases foram calculadas utilizandose uma fórmula matemática. Os resultados correspondem à retenção de leucócitos $\left(10^{3} / \mathrm{mL}\right)$ que caracteriza a AL. A proporção neutrofílica das amostras também foi calculada.

\section{Análise do MDA por espécies reativas ao ácido tiobar- bitúrico (TBARS)}

$O$ ensaio de estresse oxidativo para dosagem de malondialdeído (MDA) sérico foi o método TBARS. Para tanto, $0,1 \mathrm{~mL}$ de soro foi adicionado a $0,2 \mathrm{~mL}$ de ácido tricloroacético a $30 \%$, agitado em vortex por um minuto. Em seguida, foram adicionados $200 \mu \mathrm{L}$ de tampão Tris- $\mathrm{HCl}, \mathrm{pH} \mathrm{7,4,0,2} \mathrm{mL}$ de ácido tiobarbitúrico $0,73 \%$ e novamente a mistura foi agitada em vortex por um minuto. A mistura foi colocada em banho-maria por uma hora e em seguida foi centrifugada a $3000 \mathrm{rpm}$ durante 10 minutos e o sobrenadante foi removido e analisado em espectrofotômetro a $535 \mathrm{~nm}$. Os resultados foram calculados de acordo com uma curva padrão utilizando-se MDA a $4 \mathrm{mM}$ (Colowick et al., 1984).

\section{Análise estatística}

Os parâmetros hematológicos foram apresentados como média \pm desvio padrão para análise descritiva e inferências. Os dados referentes à taxa de $\mathrm{AL}$ foram apresentados em porcentagem os dados de MDA em média e desvio padrão. Para a comparação dos grupos na avaliação hematológica foi empregado o teste não pareado e não paramétrico de MannWhitney $(p<0,05)$. Para a comparação de grupos da análise de MDA e ensaio de AL empregou-se o teste t de Student não pareado $(p<0,05)$. Todas as análises foram realizadas com auxílio de programa estatístico Graphpad Prism 5.0 (GraphPad Software ${ }^{\circledR}$, San Diego, CA, EUA).

\section{Resultados}

\section{Análise de parâmetros clínicos e hematológicos}

Os dados referentes ao aparecimento de sinais clínicos envolvidos com a LVC estão descritos na tabela 1. Todos os animais no grupo CS apresentavam cinco ou mais sinais clínicos característicos. Os dados referentes aos hemogramas dos animais estão expressos na Tabela 2. Os animais do grupo CS apresentaram leucócitos totais $\left(12,88 \pm 3,09 \times 10^{3}\right.$ céls $\left./ \mu \mathrm{L}\right)$ e neutrófilos $\left(10,69 \pm 2,42 \times 10^{3}\right.$ céls $\left./ \mu \mathrm{L}\right)$ mais elevados quando comparados com os animais do grupo $\mathrm{CN}$ ( $p<0,01$ e $p<$ 0,001 , respectivamente). No grupo CS os valores de eritrócitos totais $(5,32 \pm 1,14, n=5)$, hemoglobina $(11,66 \pm 2,13, n=6)$ e hematócrito $(34,2 \pm 7,22, \mathrm{n}=6)$ abaixo do valor mínimo de referência para a espécie canina (Thrall, 2012) e a média desses parâmetros se apresentou reduzida quando comparada ao grupo $\mathrm{CN}(\mathrm{p}<0,05, \mathrm{p}<0,01$ e $\mathrm{p}<0,01$, respectivamente).

Tabela 1: Sinais clínicos associados à leishmaniose visceral canina em cães sintomáticos e naturalmente infectados

\begin{tabular}{cc}
\hline $\begin{array}{c}\text { Sinais clínicos fortemente } \\
\text { associados }\end{array}$ & $\begin{array}{c}\mathbf{N}^{\circ} \text { de animais acometidos } \\
\text { (total) }\end{array}$ \\
\hline Alopecia localizada/generalizada & $7(10)$ \\
Severa perda de peso & $5(10)$ \\
Lesões cutâneas & $7(10)$ \\
Onicogrifose & $7(10)$ \\
Ceratoconjutivite & $7(10)$ \\
Linfadenomegalia & $5(10)$ \\
\hline
\end{tabular}

Tabela 2: Avaliação hematológica de cães negativos e sintomáticos para leishmaniose visceral canina. Letras diferentes na mesma linha representam diferença significativa, onde ${ }^{*}=p<5 \%$, ${ }^{* *}=p<1 \%$ e ${ }^{* * *}=p<0,1 \%$. Os valores de referência para espécie canina estão de acordo com Thrall (2012)

\begin{tabular}{|c|c|c|c|}
\hline Parâmetro & $\begin{array}{c}\text { Cães Negativos } \\
\text { (CN) }\end{array}$ & $\begin{array}{l}\text { Cães Sintomáticos } \\
\text { (CS) }\end{array}$ & Referência \\
\hline Leucócitos Totais $\left(\mathrm{LT}, 10^{3} / \mu \mathrm{L}\right)$ & $9,07 \pm 2,51^{a^{* \star}}$ & $12,88 \pm 3,09^{b}$ & $6-17$ \\
\hline 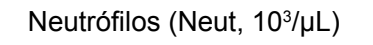 & $5,99 \pm 1,59^{a^{* * *}}$ & $10,69 \pm 2,42^{b}$ & $3-11,5$ \\
\hline Eritrócitos Totais $\left(\mathrm{ET}, 10^{6} / \mu \mathrm{L}\right)$ & $6,59 \pm 0,79 a^{a^{*}}$ & $5,32 \pm 1,14^{b}$ & $5,5-8,5$ \\
\hline Hemoglobina $(\mathrm{Hb}, \mathrm{g} / \mathrm{dL})$ & $15,46 \pm 1,76^{\mathrm{a}^{* *}}$ & $11,66 \pm 2,13^{b}$ & $12-18$ \\
\hline Hematócrito $(\mathrm{Ht}, \%)$ & $45,7 \pm 5,01^{a^{* *}}$ & $34,2 \pm 7,22^{b}$ & $37-55$ \\
\hline 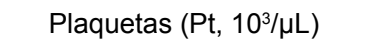 & $238,5 \pm 47,3$ & $180,1 \pm 70,3$ & $150-900$ \\
\hline
\end{tabular}

\section{Análise de adesão leucocitária}

As taxas de adesão leucocitária $(\mathrm{AL})$ nos diferentes anticoagulantes estão apresentadas na Tabela 3. No filtrado a contagem de neutrófílos foi reduzida $(p<0,05)$ nas amostras em heparina quando comparadas com citrato e EDTA (Figuras 1).

Tabela 3: Avaliação da adesão leucocitária em cães negativos e sintomáticos para leishmaniose visceral canina

\begin{tabular}{ccc}
\hline \multicolumn{3}{c}{ Adesão Leucocitária } \\
\hline Anticoagulantes & CN (n= 10) & CS (n=10) \\
Heparina & $43,45 \%$ & $55,62 \%$ \\
Citrato & $13,84 \%$ & $5,28 \%$ \\
EDTA & $9,04 \%$ & $10,46 \%$ \\
\hline
\end{tabular}




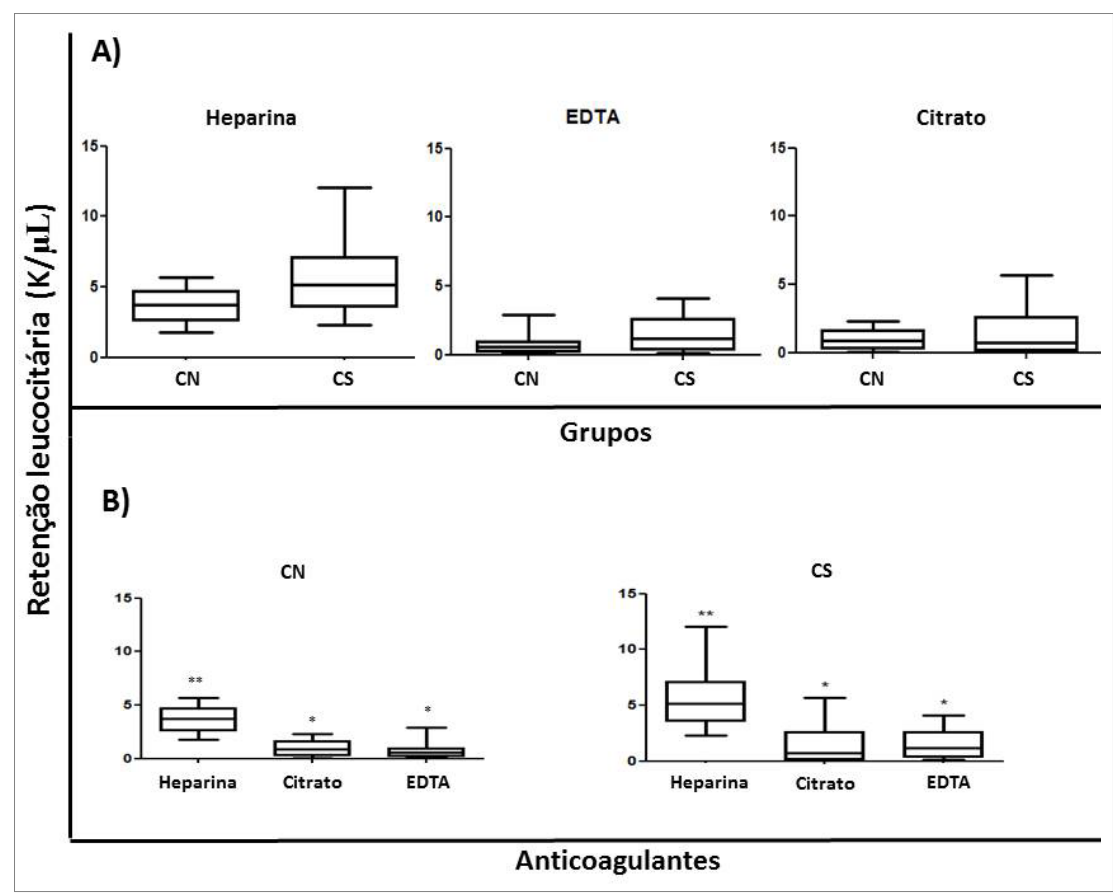

Figura 1: Proporção neutrofílica nos diferentes anticoagulantes (heparina, citrato e EDTA) (A) e nas diferentes formas clínicas (CN e CS) (B) de cães naturalmente infectados por Leishmania infantum. ${ }^{*}=p<0,05,{ }^{* *}=p<0,01 e^{* * *}=p<0,001$.

\section{Análise de TBARS}

Os níveis séricos de malondialdeído (MDA) foram estimados pelo método TBARS. Os resultados mostraram um aumento dos níveis séricos de MDA $(p<0,05)$ no grupo CS $(0,0117 \mu \mathrm{M} \pm$ $0,002)$ quando comparado com CN $(0,0057 \pm 0,001)$ (Figura 2).

\section{Discussão}

Os anticoagulantes são substâncias utilizadas para preservação de amostras de sangue, uma vez que evitam a formação de coágulos e trombos e preservam estruturas celulares e moleculares (Tecles et al., 2004). Sabe-se que os anticoagulantes têm diferentes mecanismos de ação sobre as plaquetas e sobre a cascata de coagulação em si, que por sua vez podem interferir na funcionalidade dos leucócitos e sobre a AL (Rashid et al., 2012). O uso de conservantes para a preservação, refrigeração e a estocagem de sangue canino para a análise da expressão de CD11b e da atividade da explosão respiratória foram avaliados; contudo, para estudos funcionais de neutrófilos não foram recomendadas (Ruaux e Williams, 2000).

O EDTA (ácido etilenodiaminotetracético) é o anticoagulante de escolha para hemograma devido a sua praticidade, baixo custo e segurança na preservação da amostra, sobretudo por não alterar a morfologia celular (Guzera et al., 2012). Está disponível comercialmente na forma de sal sódico ou potássico e impede a coagulação em virtude da formação de um complexo insolúvel com o cálcio, necessário para a formação do trombo (Hendrix, 2006). O Citrato também é um quelante de cálcio e, por conseguinte, exerce efeitos semelhantes ao EDTA (Erb et al., 2007). Uma vez que o cálcio é sequestrado, não há substrato para a ativação de leucócitos, e com isso, diversos processos, incluindo a AL, são suprimidos (Dhondt et al., 1998). A heparina é um anticoagulante disponível comercialmente sob a

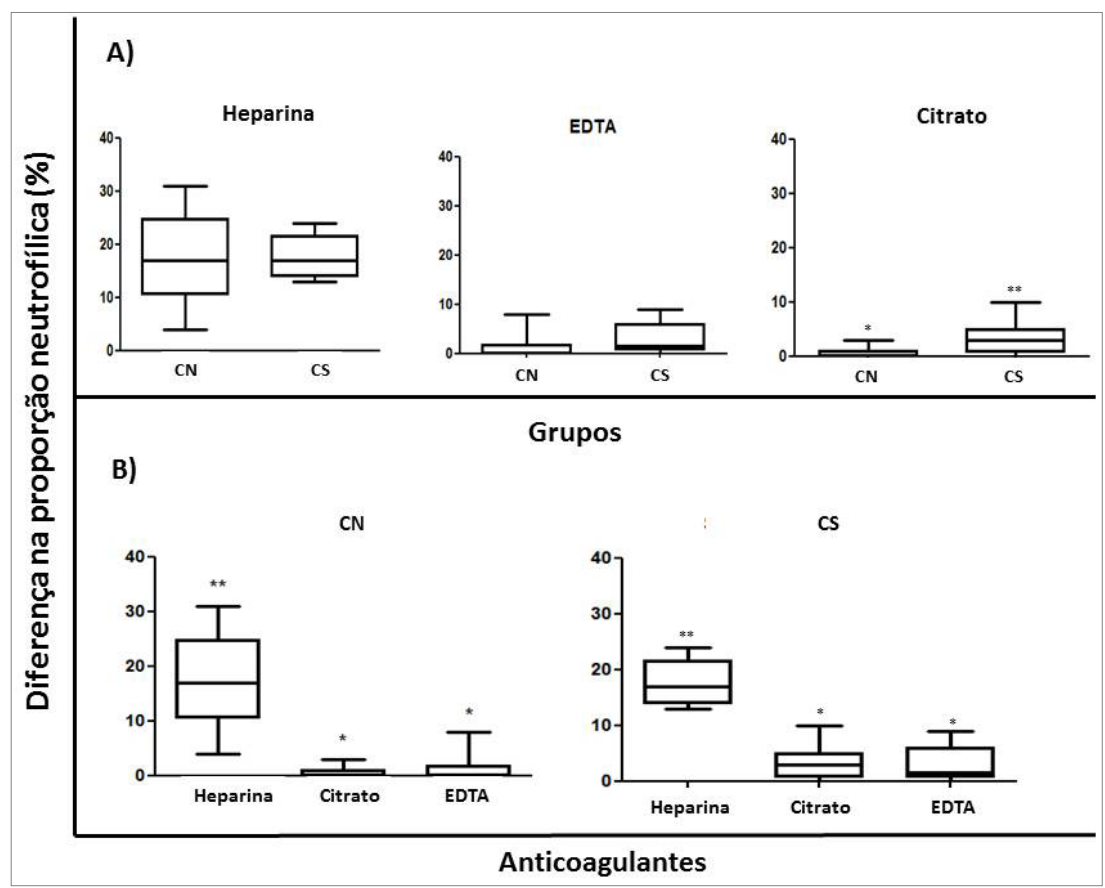

Figura 2: Níveis de Malondialdeído (MDA) sérico nas diferentes formas clínicas (CN e CS). * = $p<0,05^{* *}=p<0,01 e^{* * *}=p<0,001$. forma de sal de sódio, potássio, lítio ou amônio (Hendrix, 2006). O seu mecanismo de ação é caracterizado pelo bloqueio da conversão da protrombina em trombina, evitando assim a formação de trombos e a coagulação propriamente dita (Jackson, 1990).

No presente estudo, foi observada uma redução significativa na proporção de neutrófilos no sangue filtrado de amostras em heparina quando comparada com os outros dois anticoagulantes (figuras $1 \mathrm{~A}$ e $1 \mathrm{~B}$ ) em ambos os grupos CS e CN ( $p<0,05)$. A redução da proporção de neutrófilos no sangue filtrado é interpretada como ativação dessas células, as quais ficam retidas na malha da coluna de náilon. Os neutrófilos compreendem o principal grupo de células fagocíticas que migram através do endotélio vascular por meio da expressão de moléculas de adesão ao foco infeccioso (Weninger et al., 2014). De forma geral, a taxa de $\mathrm{AL}$ é aumentada em animais enfermos, o que sugere uma resposta imunitária associada à ocorrência de inflamação com consequente migração celular (Muller, 2012). O modelo de adesão utilizado em nosso experimento tem uma relevância na sua aplicação junto à clínica 
veterinária, sobretudo na avaliação de animais imunodeficientes de expressão de moléculas de adesão, como nos casos de deficiência de adesão leucocitária canina ou CLAD (Creevy et al., 2003; Jobling et al., 2003; Kobayashi et al., 2009).

A fim de se analisar a influência da heparina sobre AL, especificamente em células mononucleares, resultados conflitantes foram encontrados, pois tanto inibição quanto amplificação da adesão foram obtidos (Smailbegovic et al., 2001). Outros dados reforçam a utilização da heparina para avaliar a funcionalidade leucocitária, a qual deve ser realizada durante um período de até 48 horas após a coleta, de modo que a deterioração celular não interfira com os resultados (Branum et al., 1988).

ROS são metabólitos derivados do processo de estresse oxidativo que podem ser desencadeados em quadros patológicos (Abdalla e Lima, 2001). A ação dos ROS sobre lipídios induz o fenômeno da peroxidação, levando a destruição de membranas celulares (Abdalla e Lima, 2001). O produto final do processo peroxidativo é o malondialdeído (MDA), um reconhecido marcador do estresse oxidativo (Gadjeva et al., 2005). O aumento da produção de MDA sérico já foi evidenciado em cães acometidos por cânceres malignos, como carcinoma mamário, osteosarcoma, melanoma e fibrosarcoma (Boonsiri et al., 2013) e animais infectados por patógenos.

Hepatozoon canis, um parasito intracelular, provoca aumento da produção de glutationa e de óxido nítrico (NO) como resposta do hospedeiro a infecção do parasita dentro do contexto do estresse oxidativo (Kiral et al., 2005). A doença de Lyme, causada pela espiroqueta Borrelia burgdorferi, induz aumento da expressão de óxido nítrico, evidenciado pelo aumento da expressão do gene codificador da iNOS em animais infectados (Harter et al., 1999). Na osteoartrite canina, a produção de NO é um fator que influencia a degradação tecidual na (Spreng et al., 2001). A dirofilariose, doença causada pelo parasito Dirofilaria immitis, induz aumento de IL-4, II-10 e iNOS em cães infectados (Morchón et al., 2007).

No presente estudo, evidenciou-se que o grupo de cães infectados por Leishmania infantum apresentam níveis elevados de MDA quando comparados ao grupo de cães negativos (Figura 2). Resultados semelhantes foram encontrados por Heidarpour et al. (2012). Cães acometidos por sarna demodécica (Demodex canis) (Khan et al., 2013), sarna sarcóptica (Sarcoptes scabiei var. Canis) (Singh et al., 2011) e dermatofitoses (Beigh et al., 2014) também apresentam níveis séricos de MDA elevados. A babesiose (Babesia canis) também induz aumento dos níveis de MDA séricos em cães, embora não haja diferença significativa entre as formas complicada e não complicada dessa enfermidade (Crnogaj et al., 2010).

Com relação à adesão leucocitária, em função dos anticoagulantes utilizados, pode-se demonstrar que o citrato e o EDTA inibem a $A L$ tanto em cães doentes quanto saudáveis, enquanto a heparina mantém a $\mathrm{AL}$ em um nível elevado. Sendo assim, a heparina é mais apropriada para ensaios de AL. Além disso, os dados paralelos revelam um aumento dos níveis de MDA em animais afetados por LVC, podendo estar associados a uma resposta imunitária à infecção.

Conclui-se que os animais afetados pela LVC apresentam alterações nos parâmetros de adesão leucocitária e no estresse oxidativo, demonstrando a importância destes mecanismos na evolução da doença e auxiliando no diagnóstico da LVC.

\section{Agradecimentos}

Os autores gostariam de expressar seus agradecimentos ao CNPq / Brasil para a bolsa concedida ao primeiro autor, que forneceu subsídios para a implementação do projeto.

\section{Referências}

ABDALLA, D.S.; LIMA, E.S. Peroxidação lipídica: mecanismos e avaliação em amostras biológicas. Brazilian Journal of Pharmaceutical Sciences, v. 37, n. 3, p. 293-303, 2001.

ADAMS, D.H.; NASH, G.B. Disturbance of leucocyte circulation and adhesion to the endothelium as factors in circulatory pathology. British Journal of Anaesthesia, v. 77, p. 17-31, 1996.

ANDREW, N.W. Oxidative stress and intracellular infections: more iron into the fire. The Journal of Clinical Investigation, v. 122, n. 7 , p. 2352-2354, 2012.

BALDISSERA, M. D.; SOUSA, K. C. M; ANDRÉ, M. R.; GUARDA, N.S.; MORESCO, R.N.; HERRERA, H.M.; MACHADO, R.Z.; JAQUES, J.A.S.; TINUCCI-COSTA, M.; SILVA, A.S. Nitric Oxide, Protein Oxidation and Total Antioxidant Levels in Serum of Dogs Naturally Infected by Ehrlichia canis, Leishmania infantum and Babesia vogeli. Acta Scientiae Veterinariae, v. 43, p. 1320-1325, 2015.

BEIGH, S.A.; SOODAN, J.S.; SINGH, R.; KHAN, A.M.; DAR, M.A. Evaluation of trace elements, oxidant/antioxidant status, vitamin $\mathrm{C}$ and b-carotene in dogs with dermatophytosis. Mycoses, v. 57, p. 358-365, 2014.

BEVILACQUA, M.P.; NELSON, R.M.; MANNORI, G.; CECCONI, $O$. Endothelial-leukocyte adhesion molecules in human disease. Annual Review of Medicine, v. 45, p. 361-378, 1994.
BOONSIRI, P.; A.; SUKSAWAT, F.; SUKON, P.; PIMPAKDEE, K.; PATTARAPANWICHIEN, E.; TANGRASSAMEEPRASERT, R. Oxidative stress in cancer-bearing dogs assessed by measuring serum malondialdehyde. BMC Veterinary Research, v. 9, p. 101106, 2013.

BRANUM, E.; CUMMINS, L.; BARTILSON, M.; HOPPER, M.; PRUETT, S.; O'BRIEN, J.F. Effect of two anticoagulants on leukocyte yield and function, and on lysosomal enzyme activity. Clinical Chemistry, v. 34, p. 110-113, 1988.

BRASIL, M.S. Manual de Vigilância e Controle da Leishmaniose Visceral. [Control and Surveillance manual for Visceral Leishmaniasis]. Brasília: Ministério da Saúde; 2014.

COLOWICK, S.P.; KAPLAN, N.O.; PACKER, L. Methods in Enzymology. Academic Press; p. 121-125, 1984.

CREEVY, K.E.; BAUER, T.R; TUSCHONG, L.M.; EMBREE, L.J.; SILVERSTONE, A.M.; BACHER, J. D.; ROMINES, C.; GARNIER, J.; THOMAS, M.L.; COLENDA, L.; HICKSTEIN, D.D. Mixed chimeric hematopoietic stem cell transplant reverses the disease phenotype in canine leukocyte adhesion deficiency. Veterinary Immunology and Immunopathology, v. 95, p. 113-121, 2003.

CRNOGAJ, M.; PETLEVSKI, R.; MRLJAK. V.; KIS, I.; TORTI, M.; KUCER, N.; MATIJATKO, V.; SACER, I.; STOKOVIC, I. Malondialdehyde levels in serum of dogs infected with Babesia canis. Veterinarni Medicina, v. 55, n. 4, p. 163-171, 2010. 
DEBENHAM, S.L.; MILLINGTON, A.; KIJAST, J.; ANDERSSON, L.; BINNS, M. Canine leucocyte adhesion deficiency in Irish red and white setters. Journal of Small Animal Practice, v. 43, p. 7475, 2002.

DHONDT, A.; VANHOLDER, R.; WATERLOOS, M.; GLORIEUX, G.; SMET, R.; LAMEIRE, N. Citrate anticoagulation does not correct cuprophane bioincompatibility as evaluated by the expression of leukocyte surface molecules. Nephrology Dialysis Transplantation, v. 13, p. 1752-1758, 1998.

ENGELHARDT, B.; RANSOHOFF, R.M. Capture, crawl, cross: the $T$ cell code to breach the blood-brain barriers. Trends in Immunology, v. 33, p. 579-589, 2012.

ERB, H.N.; STOKOL, T. A comparison of platelet parameters in EDTA- and citrate-anticoagulated blood in dogs. Veterinary Clinical Pathology, v. 36, n. 2, p. 148-154, 2007.

FREITAS, J.C.C.; LIMA, A.L.; RODRIGUÊS, C.T.A.; ALMEIDA, G.K.G.; SANTOS, G.J.L.; ROATT, B.M.; REIS, A.B.; NUNESPINHEIRO, D.C.S. TNF- $\alpha$ and IL-10 Modulate CK and CK-MB Activities in Naturally Infected Dogs by Leishmania infantum. Acta Scientiae Veterinariae, v. 42, p. 1247-1257, 2014.

GADJEVA, V.; TODOROVA, I.; SIMEONOVA, G.; KYUCHUKOVA, D.; DINEV, D. Reference values of oxidative stress parameters (MDA, SOD, CAT) in dogs and cats. Comparative Clinical Pathology, v. 13, p. 190-194, 2005.

GONTIJO, C.M.F.; MELO, M.N. Leishmaniose Visceral no Brasil: Quadro atual, desafios e perspectivas. [Visceral leishmaniasis in Brazil: Current profile, challenges and perspectives]. Revista Brasileira de Epidemiologia, v. 7, n. 3, p. 338-349, 2004.

GUZERA, M.; ZMIGRODZKA, M.; WINNICKA, A. Comparison of the influence of EDTA-K3 and sodium citrate on haematology analysis in healthy dogs. Polish Journal of Veterinary Sciences, v. 15, n. 2, p. 391-392, 2012.

HÄRTER, L.; STRAUBINGER, R.K.; SUMMERS, B.A.; ERB, H.N.; APPEL, M.J. Up-regulation of inducible nitric oxide synthase mRNA in dogs experimentally infected with Borrelia burgdorferi. Veterinary Immunology and Immunopathology, v. 67, p. 271-284, 1999.

HEIDARPOUR, M.; SOLTANI, S.; MOHRI, M.; KHOSHNEGAH, J. Canine visceral leishmaniasis: relationships between oxidative stress, liver and kidney variables, trace elements, and clinical status. Parasitology Research, v. 111, p. 1491-1496, 2012.

HENDRIX, C.M. (Ed.). Laboratory procedures for veterinary technicians. Mosby, St. Louis, MO, p. 556, 2006.

HOLST, B.S.; HAGBERG, M.; LILLIEHÖÖK, I.; JOHANNISSON, A. Expression of four canine leukocyte adhesion factors in fresh and stored whole blood samples evaluated using a no-lyse, nowash method. Veterinary Immunology and Immunopathology, v. 139, p. 271-276, 2011.

JACKSON, C.M. Mechanism of heparin action. Baillière's Clinical Haematology, v. 3, n. 3, p. 483-504, 1990.

JOBLING, A.I.; RYAN, J.; AUGUSTEYN, R.C. The frequency of the canine leukocyte adhesion deficiency (CLAD) allele within the Irish Setter population of Australia. Australian Veterinary Journal, v. 81, n. 12, p. 763-765, 2003.

JOCHIM, R.C; TEIXEIRA, C. Leishmania commandeers the host inflammatory response through neutrophils. Trends in Parasitology, v. 25, p. 145-147, 2009.
KHAN, A.M.; BEIGH, S.A.; SOODAN, J.S.; SINGH, R. Trace minerals status and antioxidative enzyme activity in dogs with generalized demodecosis. Veterinary Parasitology, v. 198, p. 180186, 2013.

KIRAL, F.; KARAGENC, T.; PASA, S.; YENISEY, C.; SEYREK, K. Dogs with Hepatozoon canis respond to the oxidative stress by increased production of glutathione and nitric oxide. Veterinary Parasitology, v. 131, p. 15-21, 2005

KOBAYASHI, S.; SATO, R.; ABE, Y.; INANAMI, O.; YASUI, H.; OMOE, K.; YASUDA, J.; HANKANGA, C.; ODA, S.; SASAKI, J. Canine neutrophil dysfunction caused by downregulation of beta2integrin expression without mutation. Veterinary Immunology and Immunopathology, v. 130, p. 187-196, 2009.

KOLACZKOWSKA, E.; KUBES, P. Neutrophil recruitment and function in health and inflammation. Nature Reviews Immunology, v. 13, p. 159-175, 2013.

LIRA, R.A.; CAVALCANTI, M.P.; NAKAZAWA, M.; FERREIRA, A.G.P.; SILVA, E.D.; ABATH, F.G.C.; ALVES, L.C.; SOUZA, W.V.; GOMES, Y.M. Canine visceral leishmaniosis: A comparative analysis of the EIE-leishmaniose-visceral-canina-Bio-Manguinhos and the IFI-leishmaniose-visceral-canina-Bio-318 Manguinhos kits. Veterinary Parasitology, v. 137, p. 11-16, 2006.

LOPES-NETO, B.E.; LIMA, A.L.; SANTOS, G.J.L.S.; GONÇALVES, L.D.; MAIA, F.M.M.; FREITAS, J.C.C.; NUNESPINHEIRO, D.C.S. Avaliação da resposta inflamatória em cães naturalmente infectados por Leishmania infantum. Revista Brasileira de Higiene e Sanidade Animal, v. 9, n. 4, p. 645-656, 2015.

MACGREGOR, R.R.; THORNER, R.E.; WRIGHT, D.M. Lidocaine inhibits granulocyte adherence and prevents granulocyte delivery to inflammatory sites. Blood, v. 56, n. 2, p. 203-209, 1980.

MARGADANT, C.; MONSUUR, H.N.; NORMAN, J.C.; SONNENBERG, A. Mechanisms of integrin activation and trafficking. Current Opinion in Cell Biology, v. 23, p. 607-614, 2011.

MAZZONE, A.; RICEVUTI, G. Leukocyte CD11/CD18 integrins: biological and clinical relevance. Haematologica, v. 80, p. 161175, 1995.

MORCHÓN, R.; LÓPEZ-BELMONTE, J.; BAZZOCCHI, C.; GRANDI, G.; KRAMER, L.; SIMÓN, F. Dogs with patent Dirofilaria immitis infection have higher expression of circulating IL-4, IL-10 and iNOS mRNA than those with occult infection. Veterinary Immunology and Immunopathology, v. 115, p. 184-188, 2007.

MULLER, W.A. Mechanisms of transendothelial migration of leukocytes. Circulation Research, v. 105, p. 223-230, 2009.

MULLER, W.A. Getting leukocytes to the site of inflammation. Veterinary Pathology, v. 50, n.1, p. 7-22, 2012.

NAGAHATA, H.; HIGUCHI, H.; TERAOKA, H.; TAKAHASHI, K.; TAKAHASHI, K.; KUWABARA, M.; INANAMI, O.; KUWABARA, M. Decreased apoptosis of beta 2- integrin-deficient bovine neutrophils. Immunology and Cell Biology, v. 82, p. 32-37, 2004.

RASHID, Q.; SINGH, P.; ABID, M.; JAIRAJPURI, M.A. Limitations of conventional anticoagulant therapy and the promises of nonheparin based conformational activators of antithrombin. Journal of Thrombosis and Thrombolysis, v. 34, p. 251-259, 2012.

RUAUX, C.G., WILLIAMS, D.A. The effect of ex vivo refrigerated storage and cell preservation solution (Cyto-Chex IITM) on CD11b expression and oxidative burst activity of dog neutrophils. Veterinary Immunology and Immunopathology, v. 74, p. 5-69, 2000. 
SEGAL, A.W. How neutrophils kill microbes. Annual Review of Immunology, v. 23, p. 197-223, 2005.

SHALEKOFF, S.; PAGE-SHIPP, L.; TIEMESSEN, C.T. Effects of anticoagulants and temperature on expression of activation markers CD11b and HLA-DR on human leukocytes. Clinical and Diagnostic Laboratory Immunology, v.5, p. 695-7021, 1998.

SHELEF, M.A.; TAUZIN, S.; HUTTENLOCHER, A. Neutrophil migration: moving from zebrafish models to human autoimmunity. Immunological Reviews, v. 256, p. 269-281, 2013.

SINGH, S.K.; DIMRI, U.; SHARMA, M.C.; SWARUP, D.; SHARMA, B. Determination of oxidative status and apoptosis in peripheral blood of dogs with sarcoptic mange. Veterinary Parasitology, v. 178, p. 330-338, 2011.

SMAILBEGOVIC, A.; LEVER, R.; PAGE, C.P. The effects of heparin on the adhesion of human peripheral blood mononuclear cells to human stimulated umbilical vein endothelial cells. British Journal of Pharmacology, v. 1, p. 827-836, 2001.
SPRENG, D.; SIGRIST, N.; SCHWEIGHAUSER, A.; BUSATO, A.; SCHAWALDER, P. Endogenous nitric oxide production in canine osteoarthritis: Detection in urine, serum, and synovial fluid specimens. Veterinary Surgery, v. 30, p. 191-199, 2001.

TECLES, F.; CERÓN, J.J.; MARTÍNEZ-SUBIELA, S.; HENNEMANN, C. The effects of different anticoagulants on routine canine plasma biochemistry. The Veterinary Journal, v. 167, p. 294-301, 2004.

THRALL, M.A. Veterinary Hematology and Clinical Chemistry. 2 ed. United States of America: John Wiley \& Sons, 776 p.

WENINGER, W.; BIRO, M.; JAIN, R. Leukocyte migration in the interstitial space of non-lymphoid organs. Nature Reviews Immunology, v. 14, p. 233-246, 2014.

ZANDBERGEN, G.; KLINGER, M.; MUELLER, A.;

DANNENBERG, S.; GEBERT, A.; SOLBACH, W.; LASKAY, T. Cutting edge: neutrophil granulocyte serves as a vector for Leishmania entry into macrophages. Journal of Immunology, v. 173, p. 6521-6525, 2004. 